\title{
Una arquitectura adaptada al museo
}

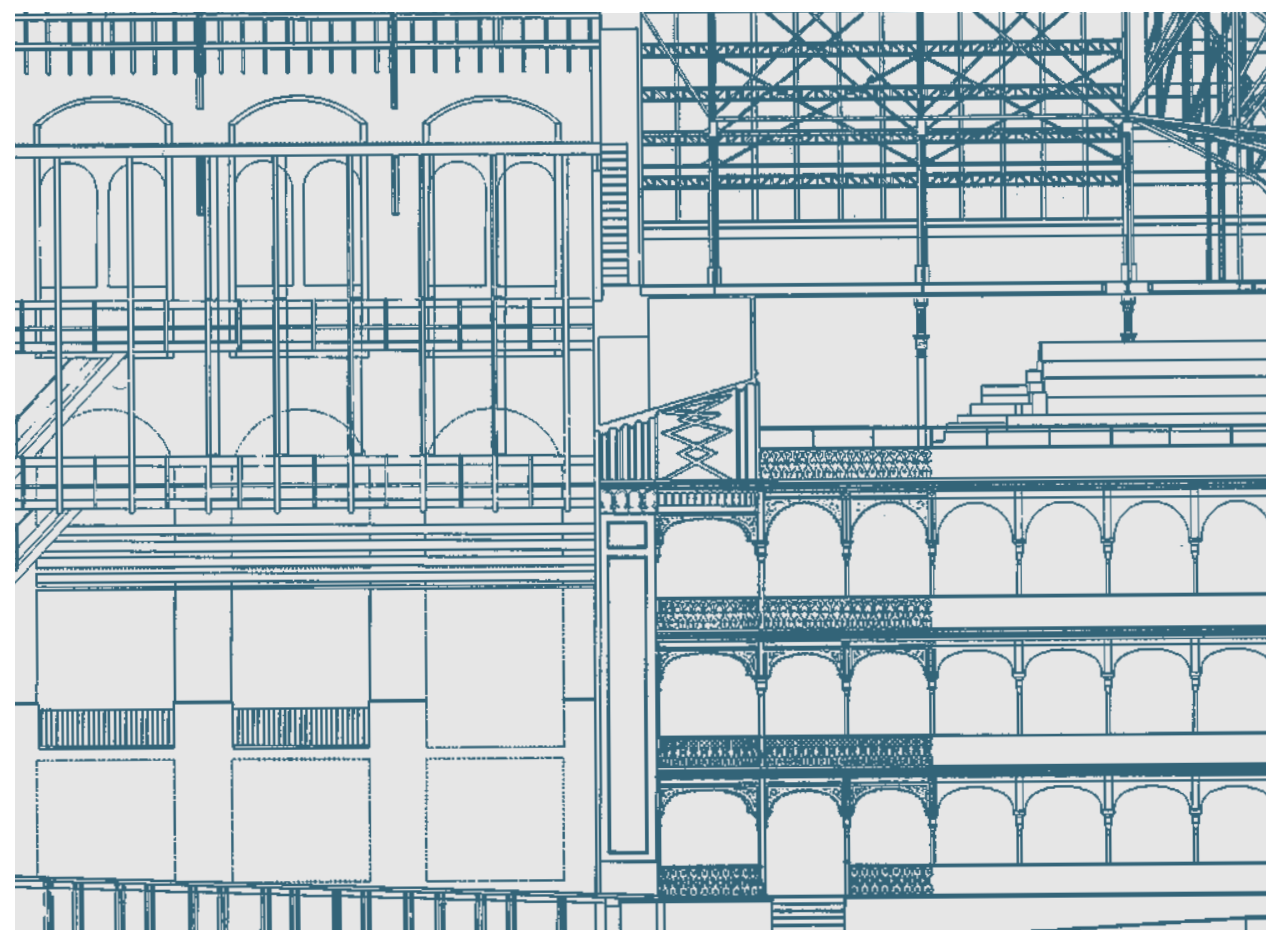

Artículo extraido de la revista MUSEUM (Copyright. UNESCO 1982. Reproduced by permission of UNESCO), a cuya dirección queremos agradecer la colaboración prestada. Hacemos también ésta extensiva a los autores.

Bernard M. Feilden Giovanni Scichilone ernard M. Feilden es arquitecto y antiguo director del Centro Internacional de Estudios de Conservación y Restauración de los Bienes Culturales (ICCROM). Antes de entrar en el ICCROM dirigía un importante taller de arquitectura y participó en múltiples proyectos: la construcción de varias universidades, de una cervecería y de una fábrica de productos químicos, entre otros. Pero su especialidad es la conservación de monumentos históricos, habiendo realizado igualmente importantes trabajos en el monasterio de York así como en las catedrales de Saint Paul y de Norwich. La calidad de toda su obra es el resultado de haber considerado que los edificios deben construir ecosistemas espaciales. 
Giovanni Scichilone nació en 1934. En 1956 se diplomó en arqueología clásica en Palermo. Recibió una beca Fullbright para estudiar en la Academia Americana de Roma en 1958-1959. Alumno de la Escuela Italiana de Arqueología de Atenas en 1960, llevó a cabo un cierto número de estudios y de tareas sobre el terreno en Italia, Grecia y Libia. Funcionario del servicio de patrimonio cultural de la administración italiana desde 1964, fue sucesivamente adscrito a la superintendencia de Etruria meridional y al Museo Arqueológico Nacional de Roma en 1976 y luego nombrado superintendente de arqueología para la región de los Abruzzos y director del Museo Arqueológico Nacional de Chieti. Consultor en materia de seguridad y de conservación del patrimonio cultural ante diversas organizaciones internacionales gubernamentales y no gubernamentales, introdujo en el museo que dirige una metodología de avanzada en estas esferas.

Museum ha entrevistado a Bernard M. Feilden y Giovanni Scichilone para plantearles algunas cuestiones fundamentales sobre el museo y la conservación y poder suscitar de este modo un intercambio de puntos de vista entre ellos. ¿Qué puede aprender de un arquitecto, que acaba de terminar un mandato de cuatro años en el puesto de director del ICCROM, un arqueólogo conservador de museo, y viceversa? La yuxtaposición de algunos de sus conceptos sorprenderá tal vez a los lectores. Sus conclusiones, lo deseamos, darán una idea más justa de todos los imperativos que deben ser tomados en consideración para llegar a realizar una verdadera conservación en un museo digno de ese nombre.

MUSEUM: Sr. Scichilone, ¿considera usted que los museos son el lugar adecuado para preservar las colecciones?

SCICHILONE: Francamente, estimo que la mayoría de los museos están equipados y organizados en forma completamente inadecuada para preservar las colecciones. Y ello pese a que durante siglos el mundo occidental ha considerado obvio y natural que colecciones de toda clase de objetos se conviertan en piezas de museo. Algunos tipos de museos - tales como los geológicos, los de historia natural y los antropológicos- fueron creados con un exclusivo propósito didáctico; los "museos de arte", sin embargo, adquirieron inmediatamente las características de lugares de "atesoramiento" (y, por consiguiente, de protección) de objetos que, de una vez por siempre, fueron considerados "valiosos"'. Es por ello que somos muchos los que en la actualidad consideramos la existencia de los museos -cualquiera sea la forma en que son administrados- en relación a la satisfacción cultural que puede aportarnos y dejando de lado el hecho de que un museo, de un cierto punto de vista, no es sino una simple "abstracción".

Pienso que el único significado duradero y objetivo de un museo es ser un lugar donde las colecciones puedan ser protegidas contra los estragos del tiempo y del hombre. Un museo que no cumpla y respete esta función como la máxima prioridad es, en mi opinión, una mera abstracción.
Sin embargo, en la mayoría de los casos, los museos no cumplen hoy sus funciones de protección. Durante los últimos treinta años las demandas para ver, exhibir y hacer circular las colecciones aumentaron enormemente. Los riesgos para las colecciones son inmensos y debemos admitir que hemos perdido objetos importantes. Durante el mismo período los museos siguieron esta evolución. Su personal recibe una formación muy similar a la que se brindaba a un conservador de hace una generación. Los antiguos museos no han sido casi modificados y la mayoría de los edificios nuevos son inadecuados porque los arquitectos raramente consideran la preservación como un factor esencial.

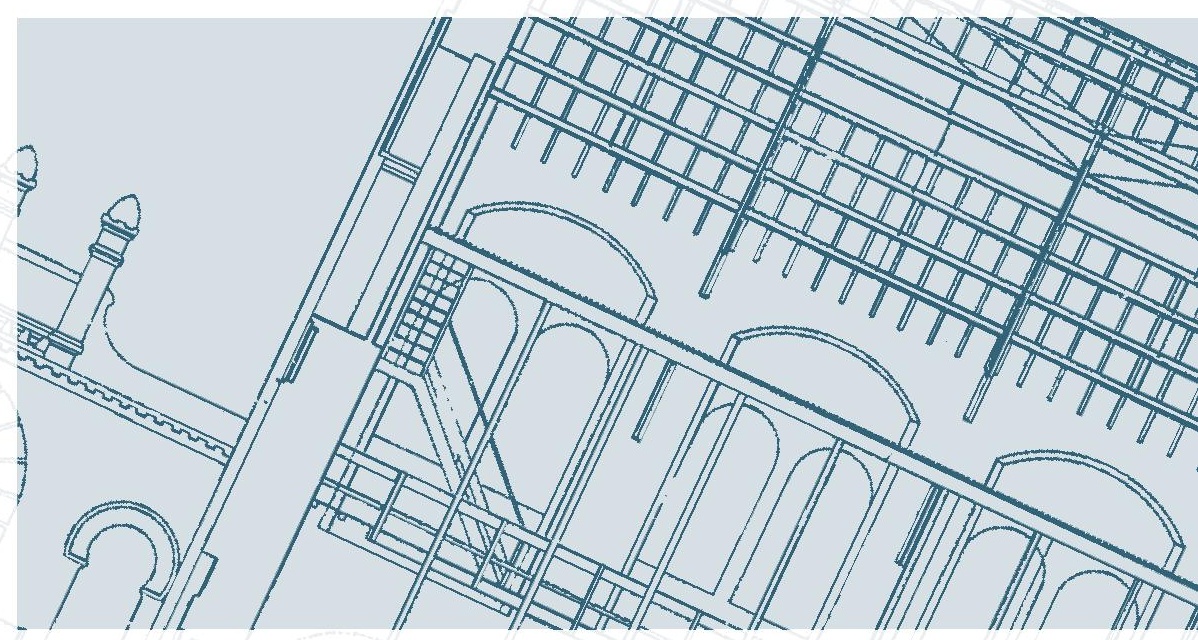

El diseño requiere un trabajo de equipo

MUSEUM: Sólo unos pocos arquitectos tienen la oportunidad de construir un museo o de adaptar un edificio antiguo. ¿Cómo elegiría usted al arquitecto?

SCICHILONE: Tendrá que tener una paciencia infinita para atender las necesidades y prioridades más dispares, pero deberá tener también mucho valor para defender "su idea" y una gran dosis de humildad para atacar los centenares de problemas que son típicos de un museo, adquirir el complejo conocimiento que probablemente no volverá a usar nunca más, escuchar a todo el mundo ( $y$ tal vez comprobar que algunas veces puede aprender de un guardián lo que un director o un conservador ha olvidado).

Durante el período de planeamiento mantendrá contactos, posiblemente difíciles, seguramente limitados: se entrevistará con el "cliente", con algunos de los asesores del cliente, con unos pocos técnicos y con uno o dos colegas. Pero no conocerá la opinión del público, conocerá probablemente sólo una reducida fracción del futuro equipo. En una palabra, sólo conocerá la parte visible de ese enorme iceberg que es el museo. Sólo una gran imaginación ("amor", tal vez) lo ayudará a proyectar una estructura suficientemente flexible. Pero también tendrá que tener la clarividencia suficiente para recordarse a sí mismo -y a otros, en caso necesario- que la validez de un proyecto de museo no se juzga por el aspecto de sus salas de exposi-

.

.


ción sino por la calidad de las instalaciones técnicas, a menudo invisibles. Un museo no debe ser sólo el medio de expresar un proyecto arquitectónico personal.

He callado deliberadamente la "experiencia científica". Conozco algunos museos espléndidos creados por arquitectos que carecían de "experiencia específica", y conozco un gran número de fracasos - para decirlo con indulgencia- proyectados con "expertos en museología". Creo que las calificaciones comúnmente llamadas "talento profesional" o "creatividad" son mucho más importantes que la llamada "experiencia científica".

Creo en la colaboración entre diferentes especialistas pero muchos museos son proyectados y construidos sólo por arquitectos y entregados entonces a un director que tiene que salvar lo que puede salvar, con la ayuda de un conservador si es suficientemente afortunado para tener uno.

MUSEUM: Sr. Feilden, ¿es verdad que los nuevos museos son proyectados y construidos sin la constante colaboración entre un director y un arquitecto?

FEILDEN: A ambos nos parece que ésta es una afirmación inconcebible. Pero esto ocurre porque los administradores tienen gran confianza en la reputación de los arquitectos, forjada por revistas de lujo que promueven sus ventas con ilustraciones de los ejemplos más extraños de arquitectos de vanguardia -a menudo con valores plásticos fascinantes- pero casi siempre carentes de utilidad práctica para los usuarios o para las colecciones. Recuerdo casos recientes, cuyos resultados fueron inmediatamente desastrosos. Conservadores independientes predijeron la catástrofe pero no fueron escuchados.

En ambos casos el arquitecto partía de una concepción previa que prosiguió con obstinación, engañándose a sí mismo y engañando naturalmente a su cliente. En ambos casos fueron proyectadas estructuras ligeras y en ambos casos aparecieron goteras en los techos y la humedad relativa fue incontrolable, con el resultado de que la colección padeció un rápido deterioro. El arquitecto lo sacrificó todo a su concepción estética en desmedro del principio de "comodidad" de los ocupantes y del contenido del museo.

En un caso, se está pensando en construir un nuevo edificio; el antiguo, construido hace sólo quince años, no durará mucho más, ya que su impermeabilización está asegurada por junturas de plásticos.

También cabe mencionar el caso de un museo inaugurado en 1968 y que nunca fue abierto al público porque la colección tiene que ser restaurada constantemente por los daños producidos por un insuficiente control de la climatización.

\section{MUSEUM: ¿Cuál sería la composición ideal de un equipo encargado de planificar un museo?}

FEILDEN: El equipo ideal debe contar con representantes del usuario y de la persona que paga por él, esto es, el cliente corriente. Los verdaderos clientes son la colección y los visitantes. Las dificultades surgen cuando el responsable de la construcción es una organización multifacética y resulta difícil lograr decisiones correctas y equilibradas. El equipo del proyecto debería incluir a un especialista en administración o dirección, un ecónomo, un conservador, un aparejador, un ingeniero competente en materia de medio ambiente y un arquitecto que debería estar apoyado, si lo desea, por un museografista o diseñador de interiores y por un arquitecto paisajista. Algunos arquitectos prefieren combinar las últimas tres funciones, y para un trabajo de gran calidad creo que esto es plausible, pero consumirá probablemente todo el tiempo de un arquitecto durante dos o tres años. Al arquitecto deberá preguntársele cómo trabaja, cuál será su participación personal y qué tareas delegará en el resto del equipo.

El administrador deberá engrasar los engranajes y vigilar la ejecución del programa. El especialista en dirección deberá realizar un estudio de todos los aspectos del museo para asegurar su funcionamiento correcto no sólo hasta el día de la apertura sino a partir de dicho día.

El director tiene la responsabilidad de la colección, debe saber qué parte de la colección debe ser expuesta, qué parte debe ser guardada, cuáles son los problemas de seguridad y cómo comunicarse con los visitantes.

El conservador aconseja al director y, a través de él, al arquitecto $y$ al ingeniero, respecto al medio ambiente apropiado para la colección, distribuyéndola en grupos según su sensibilidad a la luz, la humedad y otros factores ambientales.

El museólogo se especializa en la exposición de los objetos, teniendo presente las condiciones de medio ambiente adecuadas.

El arquitecto tiene la responsabilidad de conjunto del proyecto del edificio y de las construcciones ambientales.

El arquitecto paisajista se ocupa del entorno del edificio proyectado por el arquitecto; naturalmente, el arquitecto debe ser sensible al genius loci y a la significación simbólica del museo. El proyectista paisajista puede crear un microclima favorable en torno al museo mediante el empleo del agua, las plantas y los árboles. También puede reducir los efectos del viento y del polvo, por lo que debe ser informado también respecto a las necesidades generales del museo.

El equipo puede ser completado con un ingeniero de estructuras, quien ayudaría al arquitecto a integrar el diseño y la estructura. El especialista en servicios ambientales tiene una tarea muy especial, y debe comprender las diferencias que hay entre las necesidades del museo y las de los edificios comerciales; debe considerar la acción del edificio como un "ecosistema espacial".

El aparejador calcula los costos - una buena estimación permite al arquitecto utilizar el dinero de su cliente con el mayor rendimiento posible, una mala puede tan sólo hacer bajar los gastos finales por debajo del presupuesto, malogrando así, tal vez, el proyecto. 
Podría agregarse al equipo un consultor en materia de conservación del edificio, quien aconsejaría sobre los problemas de mantenimiento planteados por el proyecto. Debería colaborar muy estrechamente con el conservador, dado que ambos tienen por misión garantizar que el medio ambiente del museo no sea causa del deterioro de la colección.

Un buen proyecto aporta soluciones sencillas a problemas complicados. Las cualidades a las que se aspira fueron señaladas por Sir Henry Wooton, embajador de la Reina Isabel I en Venecia: "comodidad, solidez y belleza". La belleza carece de sentido sin comodidad, esto es, sin una concepción funcional que preserve la colección. Actualmente debemos considerar también la economía tanto en los costos de funcionamiento como en los de mantenimiento de los edificios. Un proyecto flexible es a la larga el más barato; la previsión debe basarse sobre unos cien años de utilización.

En este sentido, el equipo encargado del proyecto debería leer Museum environment, de Garry Thomson, y luego visitar por lo menos tres o cuatro museos y analizarlos. Entonces comenzarán todos a hablar el mismo lenguaje y a comprenderse.

Pero debemos también tener presente que a menudo los pequeños museos no pueden permitirse tener más de dos personas: un arquitecto y un director.

MUSEUM: Si el equipo se limita a un arquitecto y un director ¿el arquitecto recibe del director una información completa sobre los problemas de conservación?

FEILDEN: No. A causa de su inadecuada preparación en materia de conservación sólo unos pocos directores son capaces de informar a un arquitecto sin la ayuda de un conservador competente ${ }^{2}$.

MUSEUM: ¿Existen, a su juicio, malentendidos frecuentes entre directores de museos y arquitectos?

FEILDEN: Sí, me temo que sea así. El problema parece general, jsalvo en los casos excepcionales en los que director $y$ arquitecto son la misma personai

Estoy seguro de que el Sr. Scichilone estará de acuerdo en que el problema fundamental radica en el diálogo y en la formación de ambas partes. Como se mencionó antes, visitar museos con problemas análogos ayuda a establecer un lenguaje común. Es responsabilidad del arquitecto establecer una buena comunicación, pero el director debe tener tiempo suficiente para desempeñar bien su función.

El director medio no recibe ninguna preparación en una disciplina esencial como es la museología. Es probablemente un historiador del arte o un arqueólogo igualmente especializado. Si es un historiador del arte poseerá espíritu crítico, pero dudará de sus propias cualidades de creación. Si es un arqueólogo puede estar más interesado en usar el museo como una base para su trabajo específico. $\bigcirc$ puede querer ser director sencillamente por tratarse de un función social- mente prestigiosa. Hablo claramente y espero no resultar grosero, pero pienso que la ausencia de formación para una función importante es el origen de muchas dificultades poco aparentes de los museos. Y esta carencia de formación es una de las razones fundamentales que explica por qué tan pocos museos han sido bien proyectados.

El arquitecto puede pensar que el cometido del proyectar un museo es una oportunidad que le cae de los cielos para hacer algo grande que verdaderamente lo inmortalice. Aquí radica el peligro, porque así se olvida de la colección. Su preparación en conservación es insignificante, y aun cuando tenga la información técnica necesaria, puede ignorarla si considera que ella perturba su idea del proyecto.

Tales arquitectos tienen un don particular para proporcionar fotografías llamativas que encandilan a los clientes potenciales y a los estudiantes de arquitectura ignorantes, perpetuando así los errores de su proyecto. Yo mostré algunas fotografías de un nuevo museo en el Reino Unido a estudiantes norteamericanos -ellos lo reconocieron sin que yo dijera cuál era-, pero el breve comentario de Garry Thomson cuando salió de este museo fue: "No fue proyectado para la conservación".

Para proyectar bien, los arquitectos deben comprender los problemas de conservación. En mi opinión, si los ignoran, son legalmente culpables de negligencia, porque la información existe.

Los errores provienen de la falta de comunicación, la carencia de recursos presupuestarios racionales para las necesidades del control del medio ambiente y del almacenamiento. En la etapa de proyecto, no se consideran los problemas de mantenimiento y limpieza, ni se evalúan y previenen los peligros vinculados al clima y el medio ambiente.

Pero tal vez el fracaso mayor consista en no dar facilidades al director y al conservador para que puedan inspeccionar la colección a intervalos regulares. Tales inspecciones son la base de una conservación científica destinada a evitar el deterioro y deben tener un carácter prioritario en la concepción de un museo.

\section{MUSEUM: Sr. Scichilone, ¿qué información o instruccio- nes daría usted a un arquitecto?}

SCICHILONE: Durante cerca de un año tuve el privilegio de tener a un arquitecto con dedicación exclusiva en mi museo y por eso puedo referirme con facilidad a los provechosos resultados de nuestra colaboración. Como ocurre frecuentemente, esta joven arquitecta nunca había tenido nada que ver con un museo, pero tenía buena formación y experiencia del trabajo. Comencé proporcionándole una bibliografía técnica (como es natural, en primer término el libro de Garry Thomson) y mantuvimos amplias discusiones acerca de los museos que cada uno de nosotros había visitado y de los proyectos que conocíamos por la bibliografía.
2 Comparto totalmente la opinión de Philip Ward para quien "el error frecuente de los directores de museo y de los arquitectos consiste en diseñar -y a menudo organizar- una exposición (y a veces un museo) sin consultar a un conservador. En muchos países, esta práctica, más que cualquier otra, es la causa del descrédito de que adolece la conservación. En efecto, cuando el conservador es consultado se encuentra ante el hecho consumado, es decir, cuando ya es tarde o cuando costaría demasiado caro corregir los errores. De ahí que los consejos del conservador parezcan negativos o carentes de realismo. Por el contrario, si se le hubiera consultado antes de comenzar los trabajos, su intervención hubiera sido positiva y constructiva por la simple razón de que se la hubiera podido integrar sin dificultad". 
Seguidamente comenzamos a hablar de "nuestro problema": una amplia reconversión de nuestras superficies de exposición del museo sin ninguna intervención radical en la estructura del edificio (una quinta del siglo XIX), con una completa transformación de aproximadamente 40 por ciento de sus galerías. Queríamos exponer todo tipo de materiales arqueológicos $y$, por consiguiente, debíamos enfrentar muchos e importantes problemas de conservación. Además, ibamos a crear un salón con documentación histórico-topográfica de nuestra zona arqueológica y un salón plurifuncional para las actividades educacionales y culturales del museo.

El primer paso consistió en decidir qué y cuánto material (o grupos de material en cuestión) sería expuesto: esto requirió la colaboración del equipo científico del museo y dio a la arquitecta una idea exacta de la "dimensión" del problema.

Estuvimos de acuerdo en que nuestras prioridades eran: control del clima y de la luz, seguridad activa y pasiva de las colecciones, circulación del público (que debía ser facilitada sin modificar sustancialmente el volumen interno del edificio). Por razones de costo inicial y de mantenimiento, tratamos entonces de disponer de vitrinas modulares, de modo que pudieran ser fácilmente reunidas o usadas separadamente, según las necesidades. Finalmente, acordamos que era aconsejable mejorar la estabilidad higrométrica y térmica del edificio, entonces satisfactoria, mediante el empleo de paneles de madera donde fuera necesario, especialmente en los salones donde iban a ser expuestas las coleccione numismáticas. Esta etapa duró aproximadamente cuatro meses, y en ella la "idea" comenzó a plasmarse por sí misma de manera casi imperceptible. Entonces comenzó la fase del anteproyecto. Un año después de nuestro primer encuentro, los planes están ahora prontos para ser ejecutados y creemos que en 1982 nuestros colegas y visitantes estarán en condiciones de juzgar el resultado final de nuestra labor.

Es verdad que el nuestro fue un caso especial: teníamos que resolver una renovación parcial y contamos con una arquitecta con dedicación total que se compenetró pronto de todos los problemas del museo, de las colecciones y del personal. Sin embargo, creo que si se hubiera tratado de un proyecto de construcción nueva, o que hubiera implicado modificaciones estructurales radicales, mis prioridades hubieran sido exactamente las mismas. Si hubiera tomado una arquitecto "de afuera" le habría brindado estimaciones adecuadas sobre el número de visitantes, datos precisos sobre todas las actividades previstas para el edificio, una selección clara y definitiva de los objetos y grupos de objetos a ser expuestos y de aquellos a ser destinados a los lugares de almacenamiento, definiciones precisas respecto a las condiciones especiales de conservación de cada tipo de material. Habría insistido sobre los métodos de almacenamiento y de investigación empleados con los objetos y habría especificado todas las restricciones de acceso previstas para zonas determinadas del edificio, y una cosa más, muy importante, que a menudo se olvida: habría tratado de calcular con seguridad el ritmo de crecimiento de la colección, lo que precisamente constituye la diferencia entre la asfixia o una vida serena para nuestros museos.

\section{MUSEUM: Sr. Feilden, como arquitecto ¿habría usted pe- dido más información?}

FEILDEN: Sí, principalmente datos sobre el clima del edificio, por lo menos durante un año. Esto me permitiría descubrir con más precisión qué reacción se produce en el edificio y cuáles son los salones más adecuados desde el punto de vista de la conservación (humedad relativa estable, alta y baja humedad relativa, etc.).

En algunos países, la orientación del edificio y la ubicación de la colección pueden simplificar enormemente los problemas de conservación, sin gastos suplementarios.

MUSEUM: En su opinión, ilos directores, arquitectos y administradores tienen conciencia de los problemas de conservación producidos por el exceso de visitantes?

FEILDEN: El problema del exceso de visitantes no parece haber sido considerado. Los funcionarios se ven desbordados por turistas ansiosos, cuya experiencia se malogra porque no pueden ver el objeto y oír al guía; el museo pierde así su carácter de lugar de contemplación. El exceso de visitantes también produce daños por desgaste y facilita los actos de vandalismo. Los niños son las primeras víctimas de estos amontonamientos y tarde $o$ temprano terminan por alejarse de los museos.

Los administradores y directores deben controlar la situación y vigilarla constantemente, cómo se hace en los museos del Vaticano. Los métodos sutiles e indirectos de control de la multitud son los mejores; por ejemplo, se puede dividir a los visitantes que vienen en autobuses en tres pequeños grupos y proporcionarles guías del museo o folletos especiales que indiquen los objetos más importantes, de modo que puedan disponer libremente de su tiempo y recurrir al guía sólo para cuestiones específicas.

\section{MUSEUM: Como director de un museo, Sr, Scichilone, ¿cree usted que hay incompatibilidad entre el disfrute de una colección por un público numeroso y su conservación?}

SCICHILONE: La discusión sobre el conflicto entre conservación y usufructo es reciente y aún limitado. Presenta algunas destacadas analogías conceptuales con la más difundida y sin duda más antigua controversia sobre la relación ideal entre la circulación simplificada del conocimiento ("vulgarización") y la ciencia misma.

En este caso particular, sin embargo, el riesgo que corre un museo que difunde al máximo sus propios "contenidos" (es decir que abre ampliamente sus puertas a las multitudes que de modo creciente acuden a los museos) es el de causar a sus colecciones ciertos daños materiales a corto o largo plazo, daños que han sido científicamente probados y que son a veces irreversibles.

Además, ese daño es mucho mayor y se produce con mayor rapidez cuando el museo está sometido al de- 
terioro provocado por grupos numerosos de visitantes. Todos los directores saben que este daño es serio y progresivo, y cualquiera puede encontrar documentación impresionante e indiscutible sobre el tema.

Aún más, en el estado actual de la tecnología es prácticamente inimaginable que sea posible acceder fácilmente y a un costo accesible a equipos capaces de compensar instantáneamente todas las variaciones (de temperatura, humedad relativa, microvibraciones, carga bacterial, etc.) producidas por la asistencia diaria de miles y aun de decenas de miles de visitantes en el espacio de diez o doce horas, en un medio ambiente cerrado donde las zonas internas son relativamente pequeñas.

Desgraciadamente, el problema tiene a menudo implicaciones políticas y económicas porque, aunque es fácil calcular los ingresos engañosos que resultan de mayores ventas de publicaciones, documentos y entradas, es casi imposible calcular las pérdidas directas e indirectas, mucho mayores, producidas por el exceso de afluencia.

Hay también muchas "justificaciones" culturales (¿pseudo justificaciones?), según las cuales ese perjuicio sería compensado por los beneficios del progreso cultural.

Si esto es verdad en el caso de programas educacionales, profesionales y de proyectos, no lo es en el caso de esa misa ritual ridícula, si no trágica, organizada por las agencias de viajes en todo el mundo. En este caso la sociedad padece tanto el injustificado deterioro de las colecciones, como la inmerecida y frecuentemente irreversible circulación de pseudo ideas e inexactitudes ${ }^{3}$.

Creo que los directores de los museos que sufren este problema tienen el derecho de oponerse a este riesgo y sé que todos nosotros tenemos ahora a nuestra disposición métodos educativos y medios tecnológicos que ciertamente pueden reemplazar y mejorar ampliamente los resultados alcanzados hasta ahora por esas "visitas masivas".

\section{Mejorar la seguridad a partir del diseño}

MUSEUM: ¿Qué aconsejaría usted al arquitecto sobre los problemas de seguridad, para reducir los riesgos?

SCICHILONE: En los últimos años, aun cuando algo tardíamente, el tema de la seguridad de los museos acumuló mucha experiencia y documentación en relación con la gravedad de estos problemas. Por consiguiente, ni el arquitecto ni el director tienen dificultad en disponer de un conocimiento profundo y actualizado sobre esta materia.

Como es obvio, cuando se elabora un proyecto de museo, se debe tener presente los innumerables problemas específicos de una influencia decisiva en la calidad final del museo, especialmente respecto a medidas de seguridad contra el robo y el vandalismo.

El lugar elegido para el edificio, el volumen actual de circulación y el previsto para el futuro, el tipo de delincuencia ya conocido en la zona o la región, son todos elementos fundamentales que pueden influir en la for- ma y la estructura del edificio. El proyecto de las zonas interiores abiertas al público estará condicionado, a su vez, por el tipo de colección exhibido -con o sin vitrinas, con vitrinas pequeñas o grandes, para ser vistas a distancia, de cerca o de muy cerca-. La experiencia de otros museos puede ayudar al director a prever si, por ejemplo, el nuevo museo correrá mayor o menor riesgo de robo, de vandalismo, o de ambas cosas; además, deberá proporcionar una estimación razonablemente precisa del número promedio y del número máximo de visitantes que la colección podrá recibir por lo menos durante una década.

Estos factores facilitarán el trabajo del arquitecto para prever la disposición correcta de los objetos y de las vitrinas de exposición y, por tanto, calcular la distribución de los "refuerzos de seguridad" entre los empleados y los equipos de protección.

Por otra parte, un punto de vital importancia será el de la interrelación o la separación de las diversas funciones dentro del edificio, y aquí también la experiencia del director es un factor decisivo. Para alcanzar un alto nivel de seguridad, los lugares de almacenamiento, las oficinas, laboratorios, otras dependencias técnicas, las salas de conferencias y galerías de exposición deben ser distribuidos en el espacio disponible de modo funcional para la vida del museo, pero también de tal modo que no presenten obstáculos o riesgos, especialmente de robo.

Probablemente será más sencillo -y ciertamente dentro de la competencia del arquitecto- proteger el edificio del fuego, de los efectos de terremotos e inundaciones, pero el cliente que ordena el trabajo tiene la responsabilidad de decidir si el museo debe ser concebido para poder ser evacuado o si debe servir de "refugio sin salida".

Pienso, sin embargo, que la "filosofía" y el nivel de seguridad de un museo deben ser determinados por anticipado y con gran realismo: es inútil ensayar aparatos de seguridad de tecnología muy avanzada si uno no está seguro de poderlos hacer funcionar correctamente y tener un presupuesto adecuado. También es inútil, aunque muy frecuente, la idea de economizar haciendo elecciones de compromiso: en esta materia, sin embargo, debería dársele al arquitecto orientaciones definitivas e irreversibles.

Además, es habitual que el arquitecto mantenga una prolongada entrevista con el responsable de la seguridad del museo, o, en su defecto, con un asesor de experiencia probada. Sin embargo, yo le aconsejaría invitar a cenar, separadamente, a dos o tres porteros del museo: ni demasiado jóvenes, porque probablemente no tendrían demasiado apego por su trabajo y, de todos modos, preferirían artefactos técnicos; ni demasiado viejos, porque podrían estar demasiado cansados para pensar en el futuro del museo. Como me ha ocurrido a menudo, es posible que -con un poco de buena suerte y una botella de buen vino- el arquitecto aprenda de esa cena lo que los directores y asesores de seguridad se olvidaron de decirle.
3 Aquellos que han decidido cerrar temporariamente $\mathrm{o}$ aun definitivamente los museos o los establecimientos similares amenazados por un exceso de visitantes constituyen una minoría valiente e ilustrada. Sin embargo, en la mayoría de los casos, los conservadores y los directores están obligados a cerrar los ojos ante ciertos peligros de los que son perfectamente conscientes. 


\section{Las partes del iceberg}

MUSEUM: En su museo, ¿cuáles son los aspectos materiales que más le preocupan?

SCICHILONE: Esta pregunta puede sin duda ser entendida tanto en su sentido material como figurado, de modo que trataré de contestar brevemente desde los dos ángulos diferentes. En un sentido material, los aspectos que más me preocupan son, en primer término, los lugares de almacenamiento, luego, los servicios de documentación y de conservación, los servicios educacionales y de información, y finalmente, las galerías de exposición. Creo que toda la vida del museo, desde la investigación científica hasta la promoción de la cultura, depende de los lugares de almacenamiento a condición de que éstos estén organizados

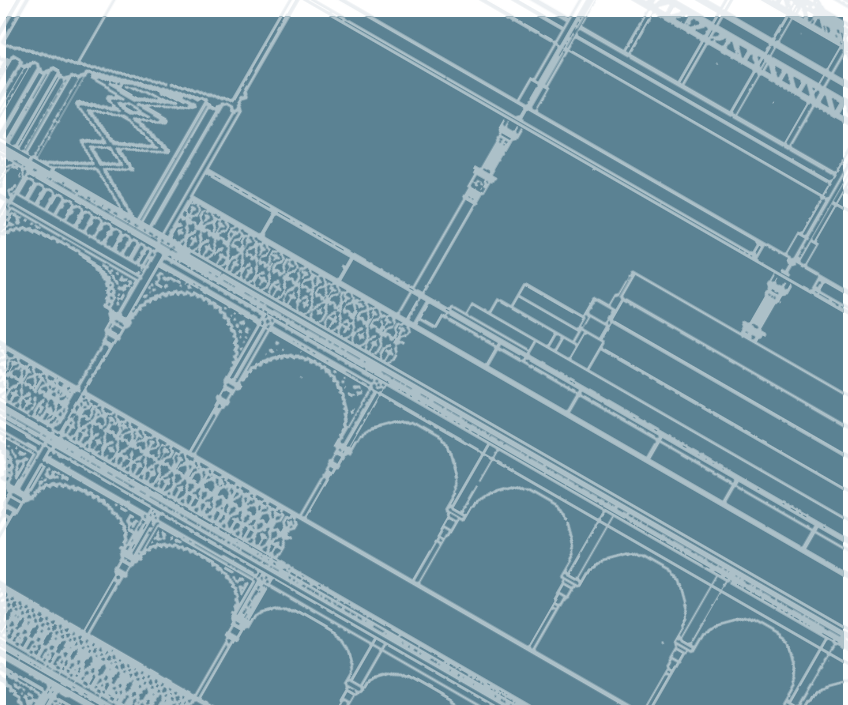

racionalmente, bien equipados, sean seguros $y$, desde luego, capaces de garantizar una conservación adecuada. Incluso los efectos de un correcto almacenamiento se advertirán en la "productividad": la rapidez y la eficacia con que se encuentra un objeto facilita el funcionamiento del servicio en su conjunto.

Los servicios de documentación y de conservación (que en mi opinión deberían tener prioridad en las distribución de las zonas y espacios del museo) son evidentemente esenciales no sólo por las razones técnicas científicas y éticas que ya mencionamos, sino también por una razón que a veces no se valora suficientemente: los efectos que produce su eficaz funcionamiento en la moral y, por consiguiente, en el rendimiento general del personal. Los visitantes sólo pueden percibir un aspecto parcial de la complejidad de nuestros problemas. Por otro lado, cualquiera que vive y trabaja en un museo no sólo tiene una visión realista de todas o casi todas nuestras limitaciones y problemas, sino también, al menos según mi experiencia, refleja en su buena o mala disposición las limitaciones o la eficiencia de la institución. Créame, es muy fácil ganar la atención y la alabanza de los demás con una exposición o la apertura de una nueva galería, pero quien dedica muchos años de su vida al museo espera con todo derecho mucho más. Además, mis colaboradores me han enseñado que la satisfacción de trabajar en buenas condiciones, con competencia profesional y con eficacia asegurada por una buena organización, cuenta mucho más de lo que los visitantes puedan imaginar.

Consideraciones análogas pueden aplicarse también a los servicios didácticos y de información. Si están equipados con los materiales necesarios, si disponen de espacio adecuado y de financiamiento suficiente, tienen una flexibilidad potencial superior a cualquiera de las otras estructuras técnicas del museo. Conozco museos donde, a pesar de grandes problemas de personal, de espacio y de financiamiento se logra realizar un trabajo excelente de promoción cultural gracias a la flexibilidad de sus programas didácticos. Como es obvio, existe el peligro de transformar la enseñanza y la información en rutina. Cuando esto ocurre, el museo cesa de transmitir cultura y se limita a difundir un producto que se asemeja tanto a la cultura como el alimento para bebé a un buen filete. Pero nuestros visitantes, gracias a Dios, son capaces a menudo de advertirnos el peligro y nos ayudan a evitarlo.

Las galerías de exposición constituyen únicamente la parte visible del iceberg. Ellas muestran nuestras limitaciones y nuestras capacidades, la imagen oficial de nuestra colección y una parte, quizás, de nuestras ilusiones. Sin embargo, dudo que puedan transmitir el mensaje final que mencioné al comienzo (el mensaje que todos soñamos con transmitir) si nos olvidamos... de la parte oculta de iceberg.

Finalmente, en un sentido figurado, las zonas de mayor preocupación en mi profesión (y no sólo en mi museo, actualmente) son la conservación, la seguridad, la promoción de la investigación científica dentro del contexto histórico-cultural que rodea al museo y la educación. Me es imposible, aquí, dedicar más de unas pocas palabras a temas tan importantes, pero reconforta señalar que en todo el mundo nuestra profesión está incesantemente ganando experiencia, precisamente en esos campos. Una de las razones -si se me permite una referencia personal- por las que yo desearía haber nacido treinta años más tarde es que actualmente quienquiera que se dedica a abrazar nuestra profesión tiene a su disposición posibilidades de aprendizaje y de formación profesional que eran completamente inimaginables hace unas pocas décadas. En la actualidad, un solo consejo será suficiente: encontrar una buena biblioteca y... leer.

\section{Del almacenamiento a la exposición}

MUSEUM: Usted acaba de acordar la prioridad absoluta al almacenamiento. ¿En su opinión, los arquitectos y directores prestan suficiente atención a la climatización de las zonas de almacenamiento?

SCICHILONE: En casi todos los museos, la zona de almacenamiento es la cenicienta, muy poco visitada por el director e incluso por los conservadores. En museos importantes, el 99 por ciento de la colección pue- 
de encontrarse en depósito. En algunos museos, donaciones recibidas una generación atrás no fueron aún desembaladas y fumigadas, aunque los donantes creen que están a salvo.

Buen almacenamiento no significa solamente buena utilización del espacio. Significa buenas condiciones climáticas, especialmente la circulación del aire hasta los rincones más alejados, para reducir los riesgos de moho y de hongos. Aunque las condiciones de clima de la zona de almacenamiento son más fáciles de controlar, tienden a ser olvidadas porque como dice el refrán "ojos que no ven, corazón que no siente". Debe dárseles prioridad porque la mayor parte de la colección se encontrará en la zona de almacenamiento.

El proyecto de las zonas de almacenamiento requiere muchos conocimientos especializados sobre cómo guardar objetos, especialmente textiles y material etnográfico, sin acelerar su deterioro. Lamento decir que este campo ha sido descuidado hasta ahora por la mayoría de los profesionales.

\section{MUSEUM: ¿Cuáles son los principales errores cometidos} en el diseño de vitrinas?

SCICHILONE: Como arqueólogo y director de un museo, yo diría que, ante todo, la vitrina es la última y la más importante "defensa activa" construida en torno a las colecciones. Es un "recipiente técnico" que debe en primer lugar y ante todo satisfacer parámetros funcionales y técnicos; la calidad estética de una vitrina para mí tiene sólo un interés accesorio, del mismo modo que para un cirujano la estética de una mesa de operaciones es de importancia secundaria. Pero a menudo se tiene la impresión de que la tentación (o la tentativa) de usar la vitrina como un ejercicio de "diseñó interior" determinó que las prioridades técnicas fuesen descuidadas.

Además, existen muchos errores técnicos asombrosamente frecuentes, pobre estabilidad estructural de la vitrina y deficiente aislamiento de las vibraciones del edificio (conozco un museo donde cada dos semanas los objetos tienen que volver a ser colocados en su lugar); pasaje de calor proveniente del equipamiento luminoso dentro de la vitrina (tanto por radiación como por conducción a través de la propia vitrina), ausencia de control espectral de la luz (aun cuando esto sea aconsejable o absolutamente necesario); pobre protección del polvo (especialmente en galerías con pisos alfombrados); escasa movilidad de los estantes interiores y, sobre todo, ausencia de "áreas técnicas" para materiales de amortiguamiento (silicato combinado, etc.) y para equipo de seguridad (cuando puede preverse su futura instalación).

Diría también que he visto algunas vitrinas que son un éxito completo desde el punto de vista del diseño $y$, sin embargo, absolutamente impecables a nivel técnico. Puede ser interesante destacar que descubrí todas sus cualidades sólo después de haber hablado con los colegas que las habían empleado. Desgraciadamente, una buena vitrina no es algo evidente.

\section{Las exposiciones temporarias e itinerantes}

MUSEUM: ¿Qué piensa usted de las exposiciones temporarias e itinerantes?

SCICHILONE: Un día tal vez alguien hable de las exposiciones itinerantes o temporarias como de una epidemia particularmente violenta que se declaró en el siglo XX de nuestra era. Constituyen sin embargo un estímulo excepcional para la vitalidad de los museos y contribuyen a la difusión cultural; pero presentan peligros extremadamente graves, y ello sin contar los peligros inherentes a la integridad de las obras expuestas. Por ejemplo, pocos museos pueden organizar una exposición importante, sin descuidar las obligaciones y la rutina cotidianas que garantizan la adecuada protección de las colecciones. Además, algunos de los principios fundamentales de la profesión de museólogo son aplicados de forma muy diferente de un museo a otro, así como objetos semejantes reciben una atención muy diversa según los museos. Incluso cuando tenemos la impresión de estar aplicando criterios idénticos, nuestros márgenes de error son diferentes. Por ejemplo, un museo puede requerir para uno de sus objetos una humedad relativa de 17 por ciento con un margen máximo de I por ciento y este requisito puede ser aceptado por otro museo al cual el objeto es prestado. No obstante, sus métodos e instrumentos para registrar y controlar el clima varían tanto que el margen máximo está realmente demasiado alejado del valor nominal requerido. Incluso en exposiciones excepcionalmente importantes he visto dispositivos de climatización en todas las salas, desconectados en su totalidad.

Además, sólo en muy pocas exposiciones el comité organizador acepta los consejos de uno o más especialistas de la conservación o de especialistas en seguridad, embalaje y trasporte. Tengo la impresión de que muchas exposiciones son organizadas de modo impecable desde el punto de vista científico y cultural, pero a menudo están improvisadas desde el punto de vista de la conservación y la seguridad ${ }^{4}$.

Tengo plena conciencia de que éste es un tema difícil y también sé que tiene implicaciones políticas complejas. Digo "políticas" en sentido literal y metafórico, tanto a nivel local como internacional. Pero también sé que la responsabilidad moral y profesional de proteger y conservar las colecciones de un museo debe incluir una cuidadosa evaluación de todos los riesgos que implica sacar a los objetos de su medio natural. Finalmente. pienso que es una actitud cínica e inaceptable la de aquéllos que, seguros del conocimiento de que disponen sobre los medios tecnológicos adecuados para el transporte y la exposición de un objeto venido de un "museo pobre", en un clima controlado, pretenden incluso ignorar que este "cambio de clima" es un trauma innegable.

A menos que los organizadores de las exposiciones -así como todos los profesionales involucradosmuestren mayor respeto por los objetos, nuestros laboratorios de restauración estarán repletos, después de la exposición, de cadáveres "impresentables". 
0
$上$
$z$
$\Sigma$
$\vdots$
0
0

\section{Medio ambiente estable}

MUSEUM: Sr. Feilden, hasta ahora usted nos ha hablado mucho de clima estable y de medio ambiente estable. ¿El aire acondicionado es una solución ideal?

FEILDEN: Para muchos directores el aire acondicionado representa la esperanza de poder liberarse de la responsabilidad de preservar sus colecciones.

Pero muy pocos museos, probablemente sólo el 5 por ciento, disponen de medios para instalar sus colecciones, en exposición o en reserva, en una atmósfera climatizada. Algunos, como el Museo Británico, instalaron pequeños equipos que funcionan dentro de las vitrinas, lo que reduce considerablemente los gastos. Sin embargo, del mismo modo que esta especie de sueño se convierte en realidad, puede también transformarse fácilmente en pesadilla, ya que el mantenimiento de un equipo de este tipo resulta muy caro y se necesitan técnicos para hacerlo funcionar. Estos técnicos muy a menudo no dependen de la misma administración que el resto del museo, lo que limita las intervenciones del conservador en materia de climatización. Además los repuestos necesarios no siempre se consiguen de inmediato; pueden producirse huelgas y cortes de energía eléctrica. La falta de recursos puede hacer necesaria la interrupción del funcionamiento durante la noche. El funcionamiento intermitente del equipo es peor que la ausencia total de climatización.

Debe recordarse también que la mayoría de las veces los ingenieros de aire acondicionado están más preocupados por el control de la temperatura que por el de la humedad relativa. Si el control de la temperatura falla, tanto los visitantes como los miembros del personal reaccionarán de inmediato, pero si el control de la humedad relativa no funciona, nadie percibirá la diferencia. Pero los objetos reaccionarán y a menudo muy intensamente.

Un consejo para quienes disponen en su museo de una unidad de aire acondicionado: emplear un termohidrógrafo para comprobar que la humedad relativa, y no sólo la temperatura, está verdaderamente estabilizada.

MUSEUM: Usted dice que el 95 por ciento de los museos no tienen una unidad de aire acondicionado. ¿Existe algún material tradicional o alguna técnica que no se adecuadamente explotada para mejorar el control de los factores climáticos en los museos modernos?

FEILDEN: En una respuesta anterior abordé este problema, pero ahora trataré de ampliar y de explicar mi frase de que un edificio es un "ecosistema espacial".

4. Me pregunto, por ejemplo, cuántos organizadores han leído la recomendación de la Unesco de 1978 sobre la protección de los bienes culturales muebles, referente a los riesgos involucrados en el transporte $y$ el tránsito de las obras de arte. ¿Cuántas exposiciones podrían llevarse a cabo si se observaran literalmente las disposiciones de esta recomendación? un volante que acumula calor durante el día desprendiéndolo por la noche y ayudando así a mantener un nivel más regular de la humedad relativa, lo que es muy favorable para la colección.

Pero los edificios, también acumulan y liberan la humedad, efecto amortiguador valioso frecuentemente ignorado. La gente y la vegetación interior aumentan la humedad. El aire transporta esa humedad en forma de vapor que puede atravesar con razonable lentitud la mayoría de los materiales de construcción, salvo si hay un aislante contra el vapor. En verano, cuando no hay calefacción, la mayoría de los edificios absorben humedad y la expelen en invierno, ayudando así a mantener la humedad relativa que se reduce por la calefacción requerida normalmente en los países de clima templado. De modo que el edificio consta de dos ecuaciones: una para incorporación y pérdida del calor, otra para pérdida y aumento de humedad, y ambas encadenan sus efectos sobre la humedad relativa del edificio. Ese es el punto esencial. El edificio es un sistema porque todos los factores se influyen recíprocamente.

Desgraciadamente la mayoría de los especialistas no consideran el edificio como un sistema. Por ejemplo, los ingenieros de luminotecnia introducen energía de calor suplementario, que deber extraer los ingenieros de aire acondicionado, o los arquitectos proyectan amplias ventanas de modo que a veces se cuadruplican las pérdidas de calor en invierno y el rendimiento del aire acondicionado en verano. Es lamentable crear problemas debido a un mal proyecto y resolverlos luego mediante equipos técnicos caros, pero esto es precisamente lo que hacen los especialistas poco competentes, para su mayor provecho. Por ello, al referirme al servicio encargado del funcionamiento, hablé de "ingeniería ambiental", porque ese servicio debe concebir el comportamiento del edificio como un sistema total. Las normas de funcionamiento exigidas por un museo son mucho más estrictas que las de los edificios comerciales.

De modo más bien irónico diría que el edificio más caro que puede imaginarse sería aquel en el que todos los especialistas hubieran aportado la solución mejor y más compleja de su especialidad. Pero lo mejor desde el punto de vista de un especialista puede ser un desastre para otro. Es el arquitecto quien debe coordinar el comportamiento ambiental global de un edificio.

En un clima árido y tórrido, o aun templado, una construcción con materiales pesados y absorbentes puede reducir en gran medida la energía necesaria para mantener el nivel de temperatura deseado y la humedad relativa necesaria para una buena conservación. Puede argumentarse que una estructura pesada es más cara, pero ello será compensado por los costos inferiores del equipo y las grandes reducciones de los gastos de energía para el mismo nivel de comodidad y de conservación.

En climas tórridos y húmedos la temperatura es casi siempre notablemente constante, por lo que hay que prestar prioritariamente atención a la circulación del aire, de modo 
que llegue hasta los rincones más aislados, donde el aire estancado facilita la proliferación del moho y los hongos. No debe olvidarse fumigar secciones enteras del museo (previendo salones no mayores de 200 metros cuadrados).

Otra dificultad reside en que el mejor y más moderno aparato mecánico envejece al cabo de diez años, incluso en menos tiempo, y si no se dispone de los repuestos necesarios, habrá que procurarse una instalación nueva. Los proyectos deben guardar relación también con las posibilidades reales de conservación existentes.

Esta digresión era necesaria para explicar cómo aprovechar los materiales y las técnicas para un mejor de control de los factores climáticos en los museos. Mis sugestiones son las siguientes:

- Emplear materiales porosos, térmicamente buenos y muy aislantes;

- Emplear la madera, sometida a buen estacionamiento y desprovista de ácidos, pues es un buen aislante y reduce los peligros de condensación;

- Emplear yeso Vermiculite, pues es un material que amortigua y también aísla; desgraciadamente es demasiado blando y no resiste a la abrasión;

- Evitar las pinturas plásticas porque obturan los materiales absorbentes;

- Evitar el hormigón armado en terminaciones de interiores y morteros con cemento porque son materiales muy pobres desde el punto de vista térmico y del aislamiento y porque provocan a menudo condensación y desprenden un polvo peligroso durante los dos primeros años;

- Asegurarse de que el edificio está bien orientado;

- Colocar las colecciones en los salones donde el clima es más adecuado;

- Colocar los objetos más delicados en vitrinas.

MUSEUM: ¿Cómo cree usted que la crisis de energía afectará a los museos en el futuro inmediato?

FEILDEN: Con todo respeto, jla crisis de la energía no es una crisis! Históricamente, hemos regresado a la situación normal en la que es cara la energía. Desde la década de 1950 vivimos en una situación artificial y me alegra que el jeque Yamani nos haya hecho volver a la realidad en 1973. Él rompió una lanza en favor de la conservación de los recursos mundiales. Esto puede sorprenderlo, pero gran parte de la arquitectura de postguerra no sobrevivirá porque resultará demasiado costosa en términos de energía. En París, un nuevo edificio de oficinas con una fachada de vidrio gasta cuatro veces más energía en verano y en invierno, por ocupante, que un edificio contiguo de hormigón armado prefabricado, no tan eficiente. Lo conveniente es disponer de una arquitectura duradera, flexible en el uso y de poca energía - poca energía en la construcción, poca energía en el mantenimiento-.

¿No es curioso que las características que acabo de señalar sean las de un edificio histórico?

En el futuro próximo la situación energética (y no de crisis) afectará sobre todo a los museos que fueron mal proyectados. En invierno la calefacción deberá ser apagada y la humedad relativa ascenderá rápidamente perjudicando la colección. En verano el aire acondicionado también tendrá que ser interrumpido y de nuevo la humedad relativa puede variar drásticamente. El director debe examinar su presupuesto, prever suficientes reservas de combustible y hacer funcionar sus equipos de modo que se puedan evitar, por lo menos, los cambios bruscos. En invierno las temperaturas serán tal vez un poco más bajas y en verano un poco más altas. Con un museo proyectado de acuerdo con las pautas que recomiendo, la misma cantidad de energía brindará seguramente buenas condiciones ambientales de conservación y, por consiguiente, la colección no correrá riesgos. Sin embargo, como las colecciones de los museos son invalorables e irremplazables, considero que los gobiernos deberían dar a los museos la misma prioridad que a los hospitales.

Cuando el clima lo permita, habrá que estudiar las posibilidades de calefacción solar mediante acumulación térmica. Si se dispone de una fuente de calor de importancia secundaria, como un río, la bomba térmica será una eficaz aplicación de energía, como lo demuestra la escuela politécnica federal de Zurich.

\section{MUSEUM: Usted nos ha hecho ver aspectos des- conocidos de la protec- ción de los museos. El vi- sitante de un museo no tiene ni idea de las difi- cultades técnicas que im- plica la protección de las colecciones, incluso den- tro de las vitrinas. ¿Pien- sa usted que sería útil explicar esto al público?}

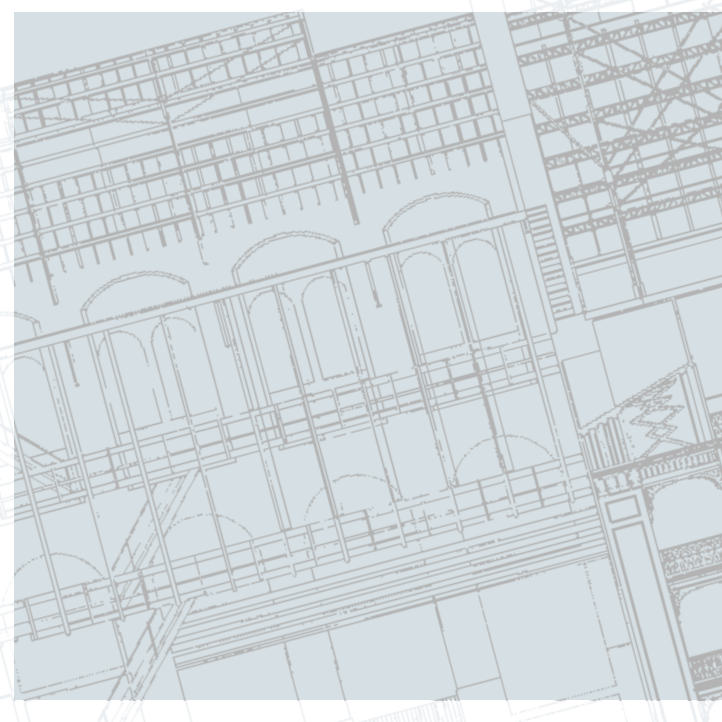

FEILDEN: No sólo es útil, sino necesario. Si, por ejemplo, no se explica que los textiles necesitan un nivel bajo de iluminación, el público se quejará de no poder apreciar bien la colección. Si no se dan explicaciones, el público no entenderá por qué los museos necesitan técnicos. Del mismo modo, si no disponen de información, los futuros arquitectos y los futuros directores seguirán cometiendo los mismos errores, y los presupuestos no proporcionarán recursos para la conservación de los museos. Algunos museos reciben a diario 15.000 visitantes, es decir 15.000 personas potencialmente dispuestas a contribuir a la obra de conservación. 